\title{
Rapid Assessment of Petroleum Hydrocarbon Contamination in Soils: Spectroscopy Approach
}

\author{
Douglas Reward Kokah $^{1,2, *}$, Aziaka Duabari Silas ${ }^{3}$, Osaribie Nelson Akeme-Esuotei ${ }^{4}$ \\ ${ }^{1}$ School of Water, Energy and Environment, Cranfield University, Cranfield, UK \\ ${ }^{2}$ National Agency for Science and Engineering Infrastructure, Garki, Abuja, Nigeria \\ ${ }^{3}$ School of Aerospace, Transport and Manufacturing, Cranfield University, Cranfield, UK \\ ${ }^{4}$ Department of Chemical and Petroleum Engineering, Niger Delta University, Wilberforce Island, Nigeria
}

Email address:

r.k.douglas@cranfield.ac.uk (D. R. Kokah), rewardkdouglas@gmail.com (D. R. Kokah), D.Aziaka@cranfield.ac.uk (A. D. Silas), nel4chem@gmail.com (O. N. Akeme-Esuotei)

${ }^{*}$ Corresponding author

\section{To cite this article:}

Douglas Reward Kokah, Aziaka Duabari Silas, Osaribie Nelson Akeme-Esuotei. Rapid Assessment of Petroleum Hydrocarbon Contamination in Soils: Spectroscopy Approach. Engineering and Applied Sciences. Vol. 4, No. 3, 2019, pp. 66-73.

doi: $10.11648 /$ j.eas. 20190403.13

Received: March 3, 2019; Accepted: July 2, 2019; Published: July 22, 2019

\begin{abstract}
Soil contamination with total petroleum hydrocarbons (TPH) as a result of crude oil exploration and exploitation activities is currently a major environmental challenge. This study proposed diffuse reflectance spectroscopy as a viable technique for rapid assessment of hydrocarbon contamination on oil spill sites in the Niger Delta, Nigeria. Spectroscopy approach was carried out in the laboratory for the prediction of TPH concentrations $\left(\mathrm{mg} \mathrm{kg}^{-1}\right)$ in genuine petroleum contaminated soils (fresh wet), as compared with analytically measured TPH concentrations. Very strong positive correlation ( $\mathrm{r}$ $=0.9686)$ was achieved between analytically and spectroscopically-predicted TPH $\left(\mathrm{mg} \mathrm{kg}^{-1}\right)$. Actual and predicted absorbance $\left(\mathrm{ABS}_{\text {act }}\right.$ and $\mathrm{ABS}$ pred, respectively) values were determined and appear not to be consistent. However, very strong positive correlation appears when each of parameter was plotted against measured TPH concentration. Diffuse reflectance spectroscopy methodology was found to be as good as the labour-intensive and expensive traditional laboratory analysis of soil PHCs and could be an alternative for laboratory methods and as a viable field-screening tool to enhance risk decision making on-site.
\end{abstract}

Keywords: Infrared Spectroscopy, Analytical Technique, Petroleum Hydrocarbon, Soil Pollution, Niger Delta

\section{Introduction}

Soil petroleum hydrocarbon (PHC) contamination is a global issue throughout the industrialized world [1]. Niger Delta region is the home of Nigeria's crude oil industries, which drive the economy of the country. Since the beginning of the establishment of oil and gas industry in the region, several oil spill incidents have been reported; and, to date, it has been estimated that 13 million tons of hydrocarbons have been spilled in the region due to pipeline fatigue, well blowout (a case in which control of well is lost during drilling operations), pipeline vandalism, and sabotage [2, 3]. Similarly, [4] reported that the number of contaminated sites in the Niger Delta region is in excess of 2000. Furthermore, the United Nation Environment Programme (UNEP) reported in 2011 that in Ogoniland alone (a small part of the Niger Delta), over 69 sites were heavily contaminated with crude oil (concentration $>139,000 \mathrm{mg} / \mathrm{kg}$ ) affecting soil, air and water quality criteria and posing a serious human health threat. This, in turn, impacts on the quality of water resources: directly affecting the health of local communities, which are drinking contaminated water $[5,6,7]$, and the aquatic flora and fauna, which is being exterminated [8]. Therefore, urgent attention is needed to clean-up these sites. However, Nigeria lacks the necessary funds, like most countries to address all the crude oil-contaminated sites (land and water) in the Niger Delta region. Thus, there is need for Nigerian government to adopt rapid measurement tools (RMT) for rapid identification of PHC contamination in soil to quicken risk-based decision making rather than relying on 
conventional laboratory analytical techniques such as gas chromatography-mass spectrometry (GC-MS). Literature revealed that the use of GC-MS is time-consuming, expensive, involves soil sampling, solvent extraction of hydrocarbon $[9,10]$.

The application of diffuse reflectance spectroscopic techniques including visible and near-infrared (vis-NIR) and mid-infrared (MIR) spectroscopy for PHCs analysis in soil was recently reviewed by [11] thus will not be repeated here. Of these studies, only one among them [12] compared results of reflectance spectroscopy TPH and laboratory measured TPH. The authors used artificially contaminated soils with PHC types (octane fuel, diesel and kerosene with known amounts of soil) for the determination of TPH using a modified version of EPA method 418.1. This method is based on extraction with 1,1, 2-Trichlorotrifluoroethane (Freon 113, GC 99.9\%). This method was originally introduced in 1978 by the United States Environmental Protection Agency (USEPA) in order to assess TPH in waste water but was later adjusted in 1983 (USEPA, 1083) for the assessment of TPH in soil. Each sample was measured for its absorbance by an infrared (IR) buck scientific analyser. The absorption was calculated for each PHC at specific concentrations, then each PHC was plotted versus the 418.1 EPA reference PHC was finally converted to TPH. After plotting reflectance spectroscopy TPH versus laboratory TPH, they concluded that reflectance spectroscopy was as good as the laboratory methods employed. The authors concluded that reflectance spectroscopy approach could be used for field-screening. However to propose spectroscopy approach for in-field hydrocarbon analysis in the future, more research is needed to confirm their finding, as there has been only a single study that used spiked samples. Thus, the current study is timely.

This study aims at investigating spectroscopy approach; and compare with traditional analytical technique (GC-MS in this study) for the measurement of TPH in genuine petroleum-contaminated soil samples. Thus, the diffuse reflectance spectroscopy approach applied in the study is discussed. Actual absorbance $\left(\mathrm{ABS}_{\mathrm{act}}\right)$ values were recorded at corresponding potential TPH signals in genuine oilcontaminated soil spectra; $\mathrm{ABS}_{\text {act }}$ values versus laboratory measured hydrocarbon concentrations plots were obtained. Predicted absorbance $\left(\mathrm{ABS}_{\text {pred }}\right)$ values were further calculated using the plot of $\mathrm{ABS}_{\text {act }}$ versus measured TPH concentration trend line; and TPH values from partial least squares regression (PLSR) chemometric analysis (spectroscopy TPH) from recent studies [9, 14, 15] versus analytically measured TPH values reported by [9] were generated.

\section{Methodology}

\subsection{Study Area and Soil Sampling}

Six petroleum-contaminated soil samples ( 2 from each site Ikarama, Kalabar and Joinkrama) were randomly selected from our previous study [9]. The study area is located in
Bayelsa and Rivers States in the Niger Delta region of Nigeria. Samples from the top 0-15 cm were collected with a shovel from the visible hot-spots in the petroleumcontaminated sites. Each sample was homogenised on-site using a hand trowel, and kept in air-tight centrifuge tubes and stored with ice blocks to avoid hydrocarbon volatilisation and preserve field-moist status until shipment to Cranfield University for further analysis. More details about the study area can be found in [9].

\subsection{Vis-NIR Soil Spectra Measurement}

The diffuse reflectance spectra of the soil samples $(n=6)$ were acquired by an ASD (Analytical Spectral Devices, Inc., USA) LabSpec $2500 \AA \quad$ Vis-NIR spectrometer with wavelength $350-2500 \mathrm{~nm}$. The spectral measurement made by ASD LabSpec $2500 \AA$ spectrometer followed the protocols described in [9]. The spectral measurements were carried out in the dark in order to both, control the illumination conditions and reduce the effects of stray light. The highintensity probe has a built-in light source made of a quartzhalogen bulb of $2727{ }^{\circ} \mathrm{C}$. The light source and detection fibres are assembled in the high-intensity probe enclosing a $35^{\circ}$ angle. The instrument was calibrated using almost $100 \%$ white-referencing material (Spectralon disc) before use, and after every thirty minutes interval... Three subsamples (fieldmoist) from each soil sample were packed into plastic Petri dishes (dimension: $1 \mathrm{~cm}$ height, $5.6 \mathrm{~cm}$ diameter) for visNIR DRS spectra measurement. To obtain optimal diffuse reflection, and hence, a good signal-to-noise ratio, samples were properly mixed with spatula, all plant and pebble particles were removed and surface was smoothened gently with a spatula for scanning [9]. Spectral measurements of all samples were recorded by placing the sample in direct contact with the high intensity probe. 10 successive spectra measurements were acquired for each sample; and further averaged in one representative spectrum of a soil sample.

\subsection{MIR Soil Spectra Collection}

MIR diffuse reflectance spectra of field-moist soil samples were collected using an Agilent 4300 handheld Fourier transfer infrared (FTIR) spectrometer (Agilent Technologies, Santa Clara, CA, United States), with spectral wavenumber range of $4000 \mathrm{~cm}^{-1}$ to $650 \mathrm{~cm}^{-1}$ at $8 \mathrm{~cm}^{-1}$ resolution and $\sim 2$ $\mathrm{cm}^{-1}$ sampling interval. Soil spectral measurement in this study followed the protocols described in [15]. A total of 32 scans were acquired per sample and these were later averaged to produce a reflectance spectrum for each individual sample using Microlab software V5.0 supplied with the spectrometer (Agilent Technologies, Santa Clara, CA, United States). This instrument was calibrated with the standard background, a silver reference cap provided by the manufacturer. A total of six $(n=6)$ field-moist oilcontaminated soil samples were placed in a $5-\mathrm{cm}$ diameter plastic Petri dishes without compression and levelled using a stainless-steel blade.

All collected spectra were converted from reflectance (R) 
to absorbance by $\log (1 / \mathrm{R})$, smoothed using the SavitzkyGolay (S-G) algorithm with a window size of 11 and polynomial of order 2 , and normalised using maximum normalization transformations. S-G algorithm was used to remove instrument noise within the spectra by smoothing the data using the polynomial regression, while normalisation of the spectra was implemented to align all spectra to the same scale and to obtain even distribution of the variances and average values [16].

\subsection{Extraction and Measurement of TPH}

Genuine oil-contaminated soil samples were analysed for TPH using sequential ultrasonic solvent extraction gas chromatography (SUSE-GC) described by [17] with some modifications. Briefly, $5 \mathrm{~g}$ of soil sample was mixed with 20 $\mathrm{ml}$ of dichloromethane (DCM): hexane (Hex) solution $(1: 1$, $\mathrm{v} / \mathrm{v})$, shaken for $16 \mathrm{~h}$ at 150 oscillations per min over $16 \mathrm{~h}$, and finally sonicated for $30 \mathrm{~min}$ at $20^{\circ} \mathrm{C}$. After centrifugation, extracts were cleaned on Florisil ${ }^{\circledR}$ columns by elution with hexane. Deuterated alkanes and PAHs internal standards were added to extracts at appropriate concentrations. The final extract was diluted (1:10) for GCMS analysis. Identification and quantification of alkanes and polycyclic aromatic hydrocarbons (PAH) were carried out using GC-MS as described by [9]. TPH concentration for each sample was obtained by summing up the alkanes and the PAH concentrations.

\subsection{Spectroscopy TPH Determination}

\subsubsection{Actual and Predicted Absorbance}

The actual absorbance $\left(\mathrm{ABS}_{\mathrm{act}}\right)$ in the genuine oilcontaminated soils was determined using the potential visNIR spectral signatures (1712, 1732 and $1758 \mathrm{~nm})$ identified by [9] and $1712 \mathrm{~nm}$ [18]. Important MIR absorption peaks between $1353-3015 \mathrm{~cm}^{-1}$ for hydrocarbons identified by [16, $19,20]$ while analysing oil-contaminated soils were used to determine $\mathrm{ABS}_{\text {act }}$. With both the vis-NIR and MIR spectra, $\mathrm{ABS}_{\text {act }}$ was determined from the graph of absorbance versus wavelength. Furthermore, laboratory TPH concentrations $\left(\mathrm{mg} \mathrm{kg}{ }^{-1}\right)$ were plotted against $\mathrm{ABS}_{\text {act }}$ and then predicted absorbance $\left(\mathrm{ABS}_{\text {pred }}\right)$ was calculated using the linear relationship that existed between the laboratory measured TPH concentration and absorbance. $\mathrm{ABS}_{\text {pred }}$ was calculated from the following concentrations: 28.44, 342.56, 101.63, $169.68,618.54$, and $653.90 \mathrm{mg} \mathrm{kg}^{-1}$ for both vis-NIR and MIR instruments.

\subsubsection{TPH Determination Using Regression Models}

Spectroscopy TPH was obtained from TPH level predicted by PLS regression models based on petroleum contaminated soils in our previous studies $[9,14,15]$. The reliability of the diffuse reflectance spectroscopy approach was evaluated by graphing laboratory measured TPH concentrations $\left(\mathrm{mg} \mathrm{kg}^{-1}\right)$ against the predicted TPH concentrations $\left(\mathrm{mg} \mathrm{kg}^{-1}\right)$ from the developed models to evaluate the correlation, $\mathrm{r}$ (strength and direction).

\section{Results and Discussion}

\subsection{Spectral Analysis of Soils}

Figure 1 shows raw vis-NIR diffuse reflectance spectroscopy absorbance spectra versus wavelength of six genuine oil-contaminated soil samples. The positions of the significant wavelengths for TPH in the six different samples are similar $(1732,1758,1712,1765,1728$, and $1785 \mathrm{~mm})$, which are close to 1712 and $1758 \mathrm{~nm}$ reported by [18]. The wavebands are not from $1752 \mathrm{~nm}$ identified by [21, 22] and [23] $1725 \mathrm{~nm}$. This confirms these wavebands to be characteristic of hydrocarbons. The significant wavebands (highlighted in red: 1732, 1712 and $1728 \mathrm{~nm}$ ) for TPH are clearer in Figure 1b, $\mathrm{c}$ and $\mathrm{f}$. Figure 1e and $\mathrm{f}$ had the highest oil concentration (Table 1) and, therefore, relatively increased absorbance. This shows that soil absorbance increases with increasing oil concentration. This agrees with the findings of [24] that soil diffuse reflectance decrease as oil concentration increases in the NIR region. This trend was not observed in Figure 1d even though the oil concentration in it was higher than that of Figure 1c. This may be associated to the effect of clay content, as clay has been reported to reduce spectral signatures for TPH calibration [25]. There are no clear useful wavebands for hydrocarbons in Figure 1a, d, and e irrespective of the presence of oil in those samples (Table 1). The unclear spectral signals may be that these samples are more wet than their counterpart samples as hydrocarbon signals in soil attenuate (reduce) as moisture content increases. The effect of clay content might be another reason since clay affect soil reflectance spectra in the NIR region [25]. The important wavebands observed in the soil spectra accords the findings in our previous studies $1712,1758 \mathrm{~nm}$ [9], $1730 \mathrm{~nm}$ [14], $1736 \mathrm{~nm}$ [15] and 1712, $1752 \mathrm{~nm}[18]$.

Table 1. Total petroleum hydrocarbon (TPH) concentrations $\left(\mathrm{mg} \mathrm{kg}^{-1}\right)$, absorbance at important wavebands associated with TPH contamination in soils, and predicted absorbance. Soil samples were collected from three petroleum release sites in the Niger Delta, Nigeria.

\begin{tabular}{lllllll}
\hline Instrument & Soil Sample & Hydrocarbon & Concentration $\left(\mathbf{m g ~ k g}^{-1}\right)$ & Waveband & ABS $_{\text {act }}$ & ABS $_{\text {pred }}$ \\
\hline \multirow{6}{*}{ Vis-NIR } & A(S1) & TPH & 101.53 & $1758 \mathrm{~nm}$ & 4.47 & 4.13 \\
& B(S1) & TPH & 653.9 & $1728 \mathrm{~nm}$ & 6.12 & 1.1 \\
& C(S2) & TPH & 169.68 & $1732 \mathrm{~nm}$ & 3.84 & 4.44 \\
& D(S2) & TPH & 342.56 & $1765 \mathrm{~nm}$ & 4.44 & 1.17 \\
\hline
\end{tabular}




\begin{tabular}{lllllll}
\hline Instrument & Soil Sample & Hydrocarbon & Concentration $\left(\mathbf{m g ~ k g}^{-1}\right)$ & Waveband & ABS $_{\text {act }}$ & ABS $_{\text {pred }}$ \\
\hline \multirow{4}{*}{ F(S3) } & TPH & 618.54 & $1712 \mathrm{~nm}$ & 5.92 & 3.79 \\
& A(S1) & TPH & 101.53 & $2873.78 \mathrm{~cm}^{-1}$ & 1.21 & 1.11 \\
\multirow{3}{*}{ MIR } & B(S1) & TPH & 653.9 & $2978.14 \mathrm{~cm}^{-1}$ & 1.58 & 1.49 \\
& C(S2) & TPH & 169.68 & $2881.23 \mathrm{~cm}^{-1}$ & 1.08 & 1.16 \\
& D(S2) & TPH & 342.56 & $2858.87 \mathrm{~cm}^{-1}$ & 1.32 & 1.28 \\
& E(S3) & TPH & 28.44 & $3019.14 \mathrm{~cm}^{-1}$ & 1.02 & 1.05 \\
& F(S3) & TPH & 618.54 & $2862.59 \mathrm{~cm}^{-1}$ & 1.41 & 1.47 \\
\hline
\end{tabular}

$\mathrm{TPH}=$ total petroleum hydrocarbon, $\mathrm{TRH}=$ total recoverable hydrocarbon, Vis-NIR=visible near-infrared, MIR=mid-infrared, $A B S_{\text {act }}=$ actual absorbance, $\mathrm{ABS}_{\text {pred }}=$ predicted absorbance, S1, S2 and S3 represent site 1, 2, and 3, respectively. $\mathrm{ABS}_{\text {act }}$ was determined from absorbance vs. wavelength plot at various wavebands associated with $\mathrm{TPH}$ while $\mathrm{ABS}_{\text {pred }}$ was calculated using the linear relationship that existed between the laboratory measured $\mathrm{TPH}$ concentration and $\mathrm{ABS}_{\text {act. }}$

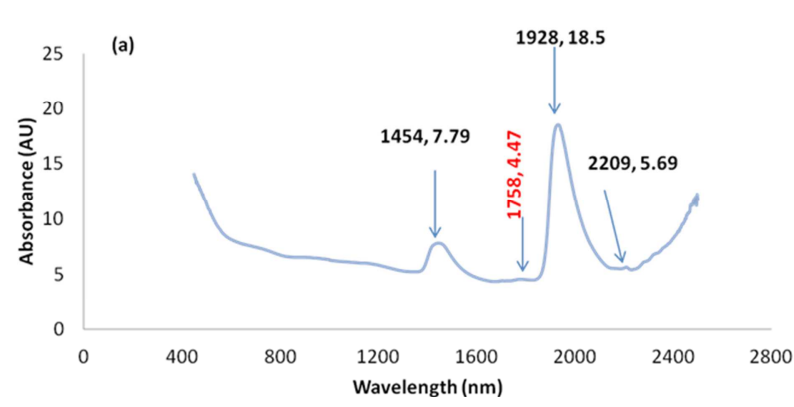

(Site 1)
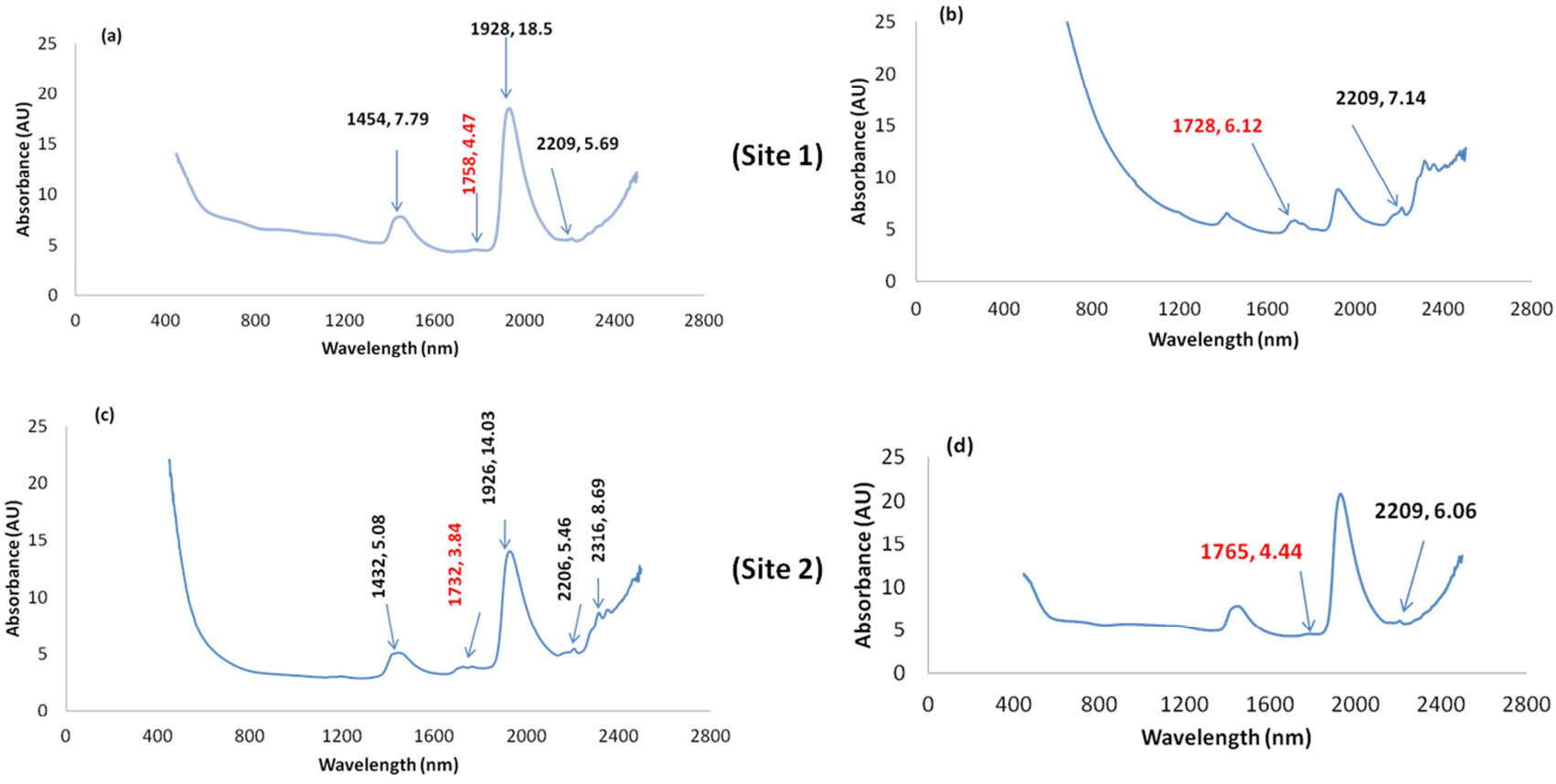

(Site 2)
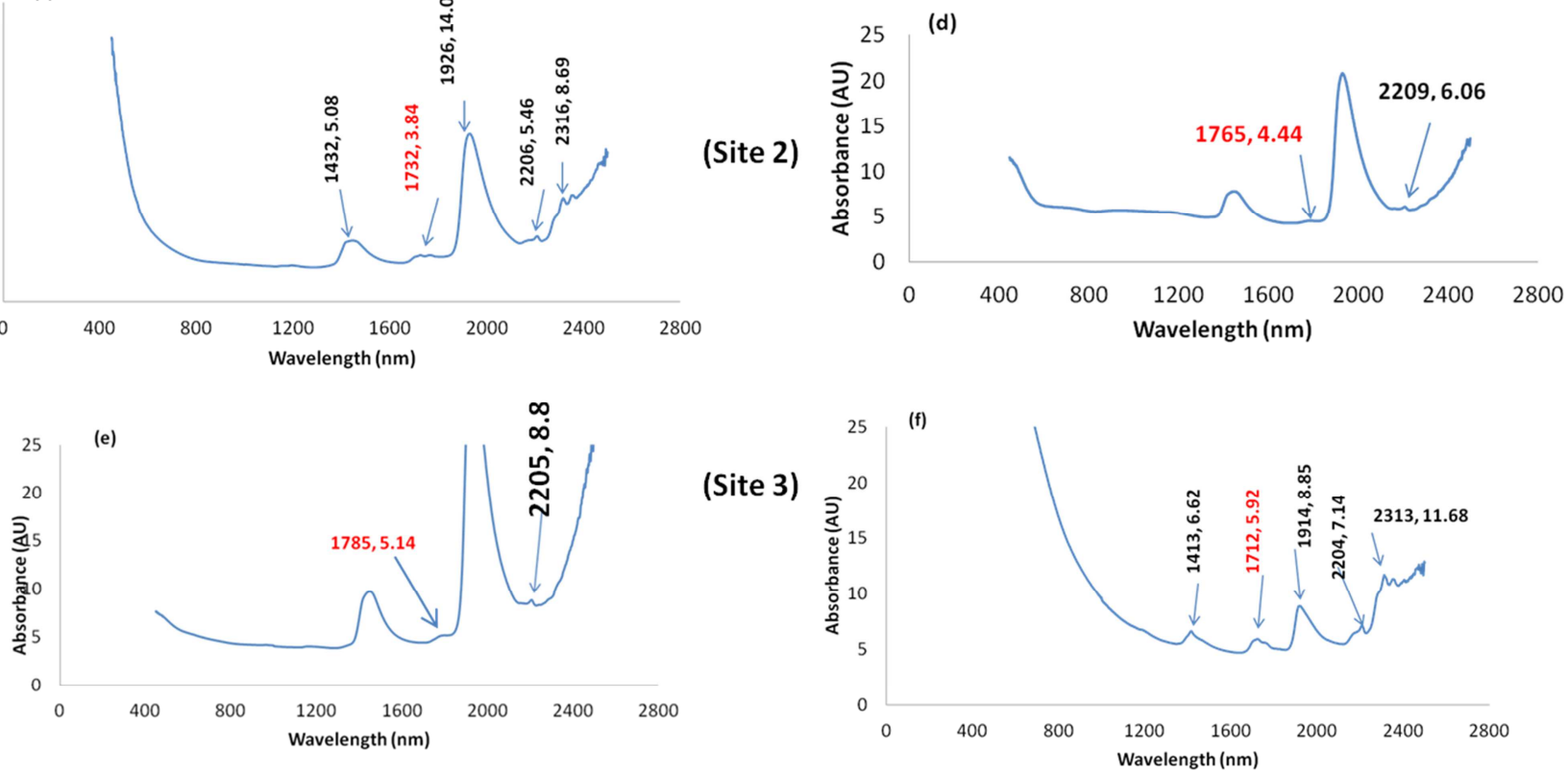

Figure 1. Vis-NIR (350-2500 nm) diffuse reflectance absorbance (AU) of contaminated soil samples collected from petroleum spill sites in the Niger Delta region of Nigeria. The wavebands highlighted in red are significant for hydrocarbon (TPH) contamination in soil and were used in the study.

Figure 2 shows raw absorbance spectrum versus wavelength of six oil-contaminated soil samples using MIR spectroscopy. Similar to the vis-NIR spectra above, the potential wavelengths for TPH (wavebands highlighted in red) are similar in all soils. This shows that both the vis-NIR and MIR sensors are sensitive to hydrocarbon concentrations in soil. Hydrocarbon signals are clearer in the absorbance curves (Figure 2a-d and f) of the soils compared to Figure 2e, which had the smallest oil concentration (Table 1). However, the expected result (the higher the oil content, the higher the absorbance) does not strictly follow the level of oil concentrations in Figure 2a-d and f. This may be connected with the effect of soil properties including clay content [25] and moisture content on soil reflectance spectra. The wavebands identified herein (Table 1) may be attributed to hydrocarbon signals in the petroleum contaminated soils. These wavelengths are close to the range 2990-2810 $\mathrm{cm}^{-1}$ previously reported by [19] to be associated with 
hydrocarbon contamination in soil. These results are not far from $2730 \mathrm{~cm}^{-1}$ reported by [25] to be specific to TPH
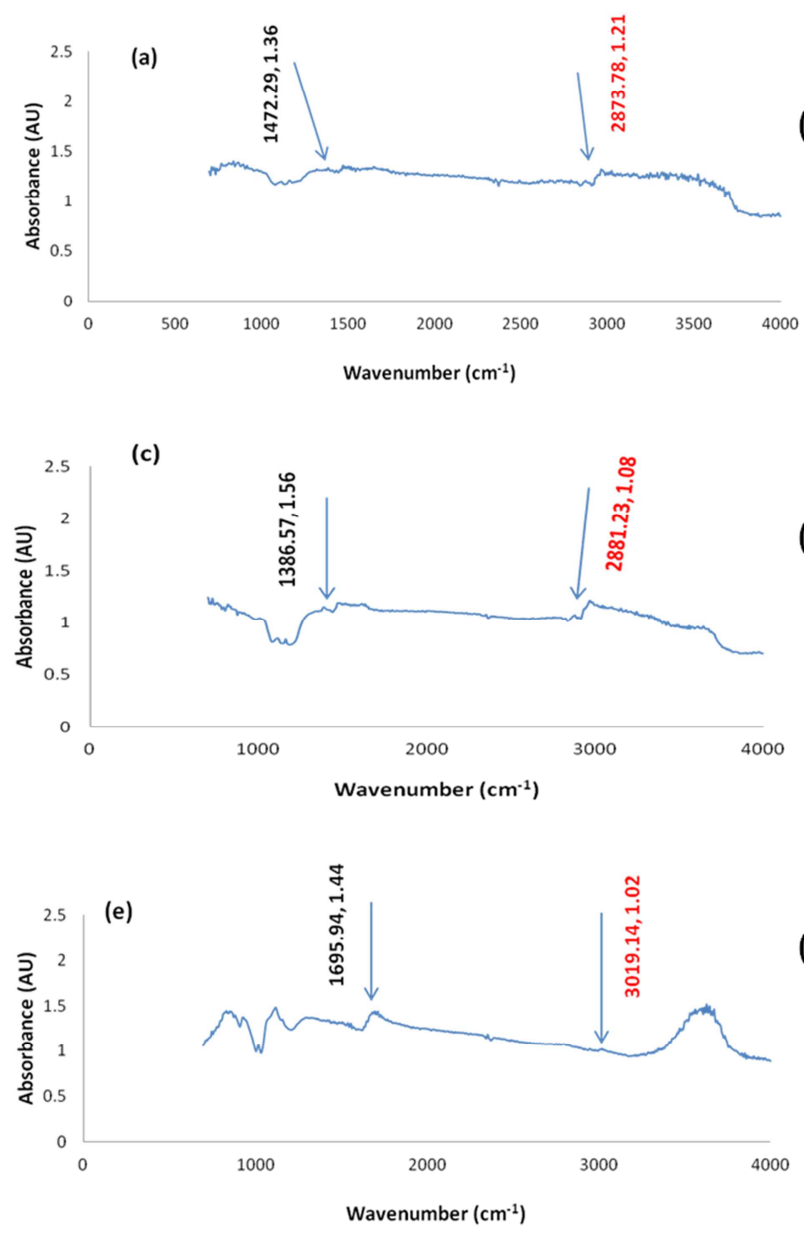

absorption in soils.

(Site 1)

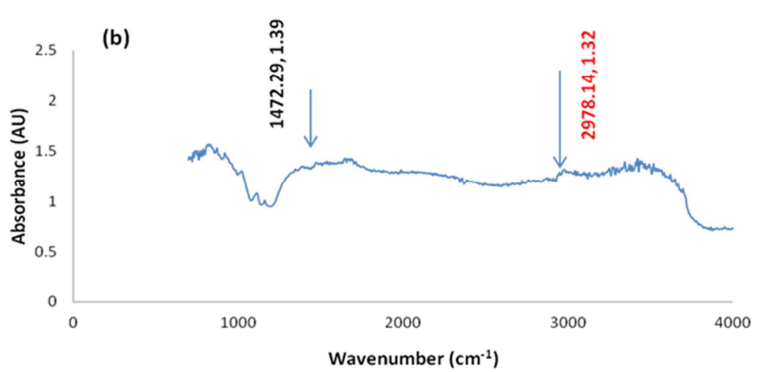

(d)

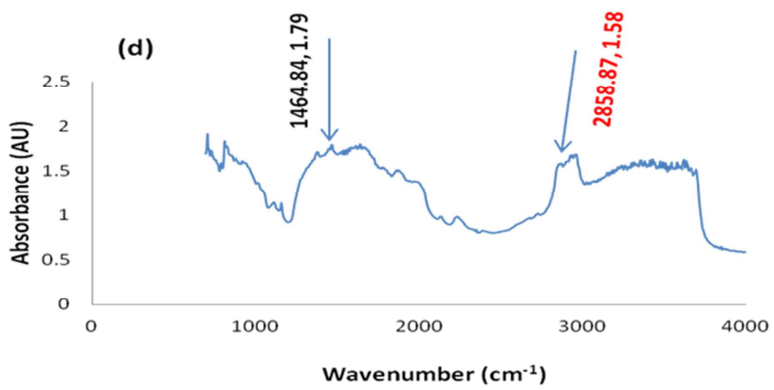

(Site 3)

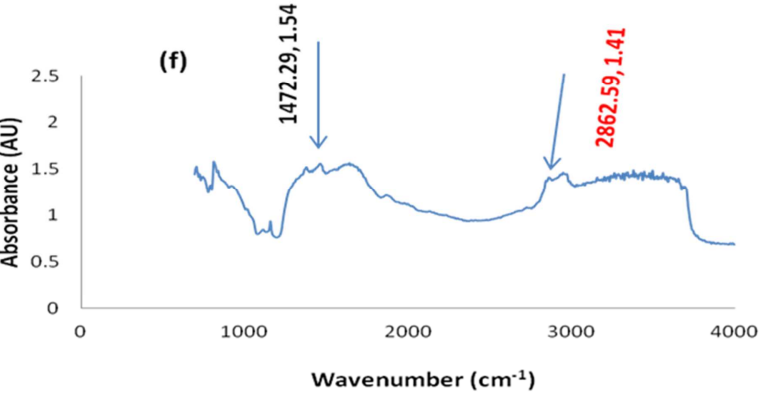

Figure 2. MIR absorbance (AU) versus wavelength $\left(4000-650 \mathrm{~cm}^{-1}\right)$. Soil samples were collected from petroleum spill sites in the Niger Delta region of Nigeria. The wavebands highlighted in red are significant for hydrocarbon contamination in soil identified in the study.
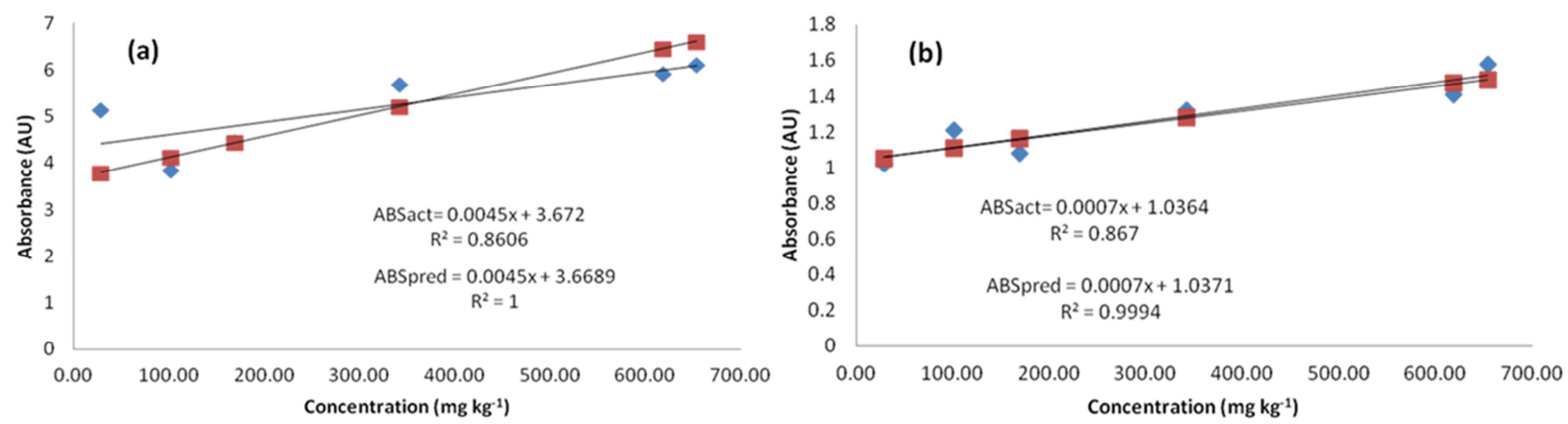

Figure 3. Spectroscopy absorbance (AU) versus GC-MS measured petroleum hydrocarbons concentration in oil-contaminated soils: (a) Vis-NIR absorbance versus TPH concentration in genuine contaminated soils collected from oil spill sites in the Niger Delta, Nigeria, (b) MIR absorbance versus TPH concentration in genuine contaminated soils collected from oil spill sites in the Niger Delta, Nigeria. The red squares and blue diamonds represent predicted and actual absorbance, respectively. ABS act was determined from absorbance versus wavelength plot at various wavebands associated with TPH whereas $A B S_{\text {pred }}$ was calculated using the linear relationship that existed between $A B S_{\text {act }}$ versus laboratory measured TPH concentration plot.

Correlation plots between absorbance values and TPH concentrations, for genuine oil-contaminated soil samples are presented in Figure 3. The absorbance for each soil sample was determined at potential wavebands associated with hydrocarbon contamination from absorbance versus wavelength plots. Figure $3 \mathrm{a}$ and $\mathrm{b}$ represent results for visNIR and MIR spectroscopy, respectively using the genuine oil-contaminated samples collected from oil spill sites in the Niger Delta, Nigeria. The results show a good correlation between the $\left(\mathrm{ABS}_{\mathrm{act}}\right.$ and $\mathrm{ABS}$ pre $)$ in each of the plots (Figure 
3). These results demonstrate that spectroscopy is a viable technique for the prediction of hydrocarbon contents in fresh oil spill sites. However, environmental factors including moist content can affect its prediction potential. Similarly, TPH overestimation may be also possible in wet chemistry due to the detection of naturally occurring hydrocarbons [26].

\subsection{TPH Concentrations in Soils}

Laboratory GC-MS measured and spectroscopy predicted TPH values for genuine oil-contaminated soil are presented in Table 2. TPH concentrations vary, however, very strong positive correlation appears from the plot of spectroscopy TPH against laboratory TPH for genuine oil-contaminated soils $(\mathrm{r}=0.9686)$ (Figure 4). This supports the findings of [26]. The correlation demonstrates that reflectance spectroscopy TPH determination approach is as good as traditional techniques for hydrocarbon analysis.

Table 2. Laboratory GC-MS measured TPH and vis-NIR spectroscopy predicted TPH in oil genuine petroleum-contaminated soils collected from Niger Delta, Nigeria. The spectroscopy TPH data is obtained from PLS model results in [9].

\begin{tabular}{lll}
\hline Soil sample & Laboratory TPH $\left(\mathbf{m g ~ k g}^{-1}\right)$ & Spectroscopy TPH $\left(\mathbf{m g ~ k g}^{-1}\right)$ \\
\hline A (S1) & 101.53 & 179.43 \\
B (S1) & 653.9 & 603.85 \\
C (S2) & 169.68 & 183.18 \\
D (S2) & 342.56 & 214.33 \\
E (S3) & 28.44 & 24.86 \\
F(S3) & 618.54 & 540.59 \\
\hline
\end{tabular}

$\mathrm{TPH}=$ total petroleum hydrocarbon, $\mathrm{S} 1, \mathrm{~S} 2$, and $\mathrm{S} 3$ represent soil sampling sites 1,2 , and 3, respectively.

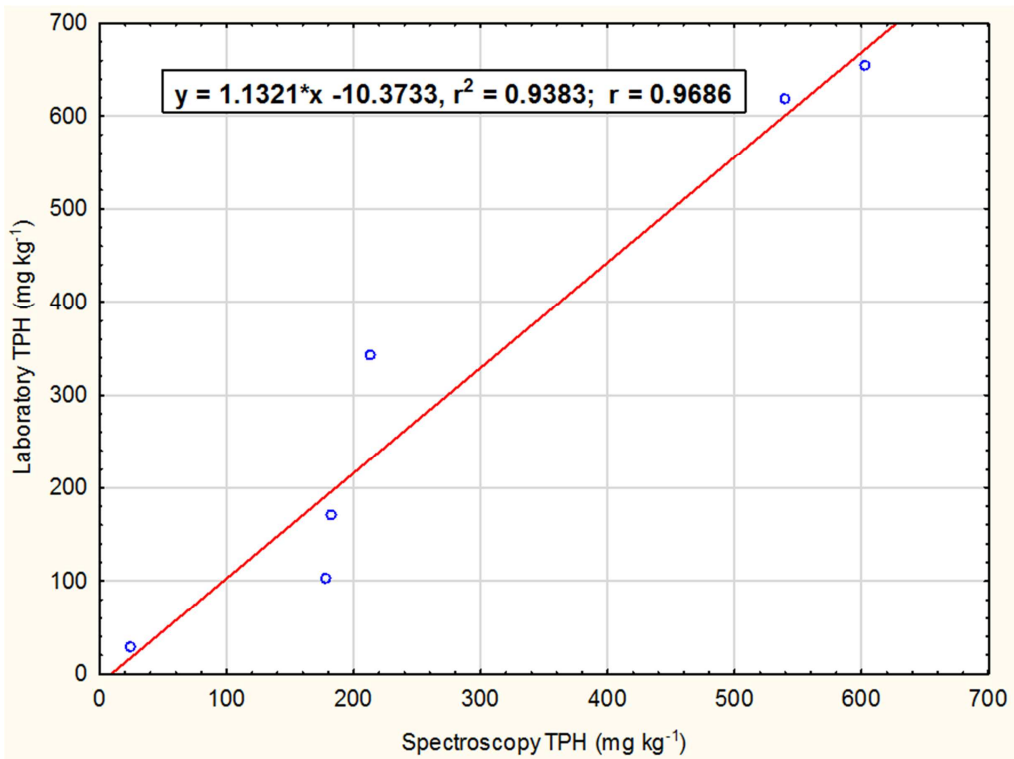

Figure 4. Scatter plot of laboratory TPH ( $\left.\mathrm{mg} \mathrm{kg}^{-1}\right)$ versus vis-NIR spectroscopy predicted TPH (mg $\left.\mathrm{kg}^{-1}\right)$ from genuine oil-contaminated soils from Niger Delta, Nigeria. $r=0.9686$ represents very strong positive correlation between laboratory GC-MS measured TPH and spectroscopy TPH for the genuine oilcontaminated soils.

\section{Conclusions}

Diffuse reflectance spectroscopy approach was applied for the assessment of petroleum hydrocarbon contents in genuine oil-contaminated soils. Both actual absorbance $\left(\mathrm{ABS}_{\mathrm{act}}\right)$ and predicted absorbance $\left(\mathrm{ABS}_{\text {pred }}\right)$ values were calculated. $\mathrm{ABS}_{\mathrm{act}}$ values were recorded at corresponding potential TPH signals in the plots of spectral absorbance against wavelength whereas $\mathrm{ABS}_{\text {pred }}$ values were calculated using the trend line obtained from the graph of $\mathrm{ABS}_{\text {act }}$ versus analytically measured TPH concentrations. Results show that $\mathrm{ABS}_{\text {act }}$ and $\mathrm{ABS}_{\text {pred }}$ values vary slightly. Vis-NIR and MIR absorbance versus GC-MS measured TPH concentrations plots for genuine petroleum hydrocarbon-contaminated soils were generated; and very strong positive correlation existed between spectroscopy predicted TPH and absorbance $\left(\mathrm{ABS}_{\mathrm{act}}\right.$ and $\left.\mathrm{ABS}_{\mathrm{pred}}\right)$ values. However better results were obtained with the $\mathrm{ABS}_{\text {pred }}$. Furthermore, plots of analytically measured TPH ( $\left.\mathrm{mg} \mathrm{kg}^{-1}\right)$ values versus vis-NIR spectroscopy predicted TPH $\left(\mathrm{mg} \mathrm{kg}^{-1}\right)$ for genuine petroleum hydrocarboncontaminated soil showed very strong positive correlation ( $\mathrm{r}$ $=0.9686$ ). Thus, reflectance spectroscopy approach is as good as traditional laboratory technique for hydrocarbon contents measurement in soil. Considering the advantages of reflectance spectroscopy over the analytical techniques, such 
as rapid analysis time, use of no extraction solvent, little or no sample preparation, and the consequent costeffectiveness; diffuse reflectance spectroscopy approach applied herein is a viable alternative for rapid soil hydrocarbon contamination assessment and identification of petroleum-contaminated sites. However, future work is recommended to investigate this methodology with more samples, use soils from various petroleum release areas to cover large variability of soil types.

\section{References}

[1] Brassington, K. J., Hough, R. L., Paton, G. I., Semple, K. T., Risdon, G. C., Crossley, J., Hay, I., Askari, K., Pollard, S. J. T, 2007. Weathered hydrocarbon wastes: a risk assessment management primer. Crit. Rev Environ Sci Technol 37, 199 232.

[2] Ambituuni, A., Amezaga, J., Emeseh, E., 2014. Analysis of safety and environmental regulations for downstream petroleum industry operations in Nigeria: Problems and prospects. Environ. Dev. 9, 43-60. doi: http://dx.doi.org/10.1016/j.envdev.2013.12.002.

[3] Nwilo, P. C., Badejo, O. T., 2006. Impacts and management of oil spill pollution along the Nigerian coastal areas. Adm. Mar. Spaces Int. Issues 119.

[4] Ite, A. E., Ibok, U. J., Ite, M. U., Petters, S. W., 2013. Petroleum Exploration and Production: Past and Present Environmental Issues in the Nigeria's Niger Delta. Am. J. Environ. Prot. 1, 78-90.

[5] Davies, O., and Abolude, D. (2016). Polycyclic aromatic hydrocarbons (pahs) of surface water from Oburun Lake, Niger Delta, Nigeria. Appl. Sci. Res. 13, 20-24.

[6] Nganje, T. N., Hursthouse, A. S., Edet, A., Stirling, D., and Adamu, C. I. (2015). Hydrochemistry of surface and groundwater in the shale bedrock, Cross River Basin and Niger Delta region, Nigeria. Appl. Water Sci. 7, 961-985.

[7] United Nations Environment Program, (2011). Environmental Assessment of Ogoniland. UNEP, Switzerland.

[8] Luiselli, L., Amori, G., Akani, G. C., and Eniang, E. A. (2015). Ecological diversity, community structure and conservation of Niger Delta mammals. Biodivers. Conserv. 24: $2809-2830$.

[9] Douglas, R. K., Nawar, S., Alamar, M. C., Mouazen, A. M., Coulon, F., 2018a. Rapid prediction of total petroleum hydrocarbons concentration in contaminated soil using visNIR spectroscopy and regression techniques. Sci. Total Environ., 616-617, 147-155.

[10] Okparanma, R. N., Mouazen, A. M., 2013. Combined effects of oil concentration, clay and moisture contents on diffuse reflectance spectra of diesel-contaminated soils", Water, Air and Soil Pollut. 224 (5), 1539-1556.

[11] Douglas, R. K., Nawar, S., Alamar, M. C., Coulon, F., Mouazen, A. M., 2017. Almost 25 years of chromatographic and spectroscopic analytical method development for petroleum hydrocarbons analysis in soil and sediment: stateof-the-art, progress and trends. Crit. Rev Environ Sci Technol., 47 (16), 1497-1527.
[12] Schwartz, G., Ben-Dor, E., and Eshel, G., 2012. Quantitative analysis of total petroleum hydrocarbons in soils: comparison between reflectance spectroscopy and solvent extraction by 3 certified laboratories. Appl. Environ. Soil Sci., 2012, 1-11

[13] United States Environmental Protection Agency (USEPA)., 1978. Test Methods for Evaluating Total Recoverable Petroleum Hydrocarbons, Method 418.1 (Spectrophotometric, Infrared), Government Printing Office, Washington, DC, USA.

[14] Douglas, R. K., Nawar, S., Alamar, M. C., Mouazen, A. M., Coulon, F., 2018a. Rapid prediction of total petroleum hydrocarbons concentration in contaminated soil using visNIR spectroscopy and regression techniques. Sci. Total Environ. 616-617, 147-155.

[15] Douglas, R. K., Nawar, S., Alamar, M. C., Mouazen, A. M., Coulon, F., 2019. The application of a handheld mid-infrared spectrometry for rapid measurement of oil contamination in agricultural sites. Sci. Total Environ. 665 (2019) 253-261.

[16] Rinnan, A., Van Den Berg, F., Engelsen, S. B., 2009. Review of the most common pre-processing techniques for nearinfrared spectra. TrAC Trends Anal. Chem. 28, 1201-1222.

[17] Risdon, G. C., Pollard, S. J. T., Brassington, K. J., McEwan, J. N., Paton, G. I., Semple, K. T., and Coulon, F., 2008. Development of an analytical procedure for weathered hydrocarbon contaminated soils within a UK risk-based framework. Anal. Chem. 80, 7090-7096.

[18] Okparanma, R. N., Coulon, F., Mouazen, A. M., 2014. Analysis of petroleum-contaminated soils by diffuse reflectance spectroscopy and sequential ultra sonic solvent extraction-gas chromatography. Environmental Pollut. 184, 298-305.

[19] Wartini, Ng., Brendan, P. M. \& Budiman, M., 2017. Rapid assessment of petroleum-contaminated soils with infrared spectroscopy. Geoderma, 289, 150-160.

[20] Webster, G. T., Soriano-Disla, J. M., Kirk, J., Janik, L. J., Forrester, S. T., McLaughlin, M. J., Stewart, R. J., 2016. Rapid prediction of total petroleum hydrocarbons in soil using a handheld mid-infrared field instrument. Talanta 160, 410-416.

[21] Chakraborty, S., Weindorf, D. C., Li, B., Aldabaa, A. A. A., Gosh, R. K., Paul, S., Ali, M. N., 2015. Development of a hybrid proximal sensing method for rapid identification of petroleum contaminated soils. Science of the Total Environment. 514, 399-408.

[22] Osborne, B. G., Fearn, T., Hindle, P. H., 2007. Practical NIR Spectroscopy with Applications in Food and Beverage Analysis, second ed. Longman Group UK Limited, England.

[23] Mullins, O. C., Mitra-Kirtley, S., Zhu, Y., 1992. The electronic absorption edge of petroleum. Appl. Spectrosc. 46, $1405-1411$.

[24] Okparanma, R. N., Mouazen, A. M., 2013. Combined effects of oil concentration, clay and moisture contents on diffuse reflectance spectra of diesel-contaminated soils", Water, Air and Soil Pollut. 224 (5), 1539-1556.

[25] Forrester, S., Janik, L., McLaughlin, M., 2010. An infrared spectroscopic test for total petroleum hydrocarbon (TPH) contamination in soils, Proceedings of the 19th World Congress of Soil Science, Soil Solutions for a Changing World, Brisbane, Australia, August 1-6, 13-16. 
[26] Schwartz, G., Ben-Dor, E., and Eshel, G., 2012. Quantitative analysis of total petroleum hydrocarbons in soils: comparison between reflectance spectroscopy and solvent extraction by 3 certified laboratories. Appl. Environ. Soil Sci., 2012, 1-11. 